\title{
Positron Emission Tomography in Psychiatric and Neuropsychiatric Disorders
}

\author{
R. J. Dolan, M.D.* and K. J. Friston, M.A., (Cantab)†
}

Positron emission tomography (PET) has a potentially unique position in the study of psychiatric and neuropsychiatric disorders. The mechanisms by which regional pathologic changes disrupt normal psychologic functioning and the relationships between mental events and brain physiology are now open to empirical study. Although progress has been made in revealing the functional anatomy of human cognition, PET has not, as yet, clarified the pathologic processes underlying the major psychiatric disorders. This failure may mean that the processes mediating psychiatric disorders are beyond the resolution of PET or, alternatively, that the design of PET studies of psychiatric disorders is not sufficiently refined.

The primary focus of PET studies up to the present has been the investigation of neurologic disorders. In the application of PET to psychiatric research it is important to bear in mind essential differences between psychiatric and neurologic disorders. Psychiatric illness involves the disorganization of internal experience as opposed to the breakdown of primary sensorimotor function. Arguably PET methodologic strategies that have proved fruitful in the study of neurologic disorders, where there are fixed pathologic features, may be inappropriate to the study of psychiatric disorders. In psychiatric disorders, with no fixed pathologic features, abnormalities are likely to be "functional," involving disturbed neural integration. Therefore novel strategies or augmentation of existing methods will be necessary in the investigation of these disorders.

The choice of appropriate PET methods for data acquisition and analysis in studies of ps atric disorders has still to be established. T normal responsivity of psychiatric patients chologic and physical stressors makes sca conditions critical. It can be argued that state metabolic scans should be augmente studies during the performance of cognitive or during specific pharmacologic manipula Most PET studies reported to date have bee quired under resting conditions and this may tially explain the lack of consistent findings. absence of standardized approaches to PET i analysis in circumstances where little is known cerning regional pathologic characteristicsisa ther drawback and has led to an excess reliane ratio data. This type of approach can often be leading because such relative values have shown to be highly sensitive to ambient cono The seemingly arbitrary region of interest tion reported in the literature emphasizes the for standardized methods of region of it definition or the exploration of alternatit proaches.

As well as issues of study design, eq must be applied to patient selection and cha ization. Homogeneity of the patient group damental in psychiatric studies. Lack of hio neity can render relationships between groups and PET measures extremely elusi homogeneity is difficult to achieve using sectional assessments, which are standard chiatric research. Such methods need to be mented by either longitudinal assessments use of genetic or other such biologic marker

\footnotetext{
*National Hospital and Academic Department of Psychiatry, Royal Free Hospital Medical School, London, United Kingdom

† MRC Cyclotron Unit, Hammersmith Hospital, and Department of Psychiatry, Charing Cross and Westminster Medical Schools, London, United Kingdom.

Reprint requests: Dr. Dolan, Academic Department of Psychiatry, Royal Free Hospital Medical School, London, UK

Copyright (C) 1989 by Thieme Medical Publishers, Inc., 381 Park Avenue South, New York, NY 10016. All rights reserved.
} 
sing and remitting nature of many psychiatric fers emphasizes the need for appropriate of studies in relation to clinical state. is article examines findings from PET studpatients with psychiatric and neuropsychiatsorders and highlights areas of current and Finterest. Most studies have concerned the psychiatric disorders, schizophrenia and afdisorders, and consequently the greater of this article will address findings in these ions.

\section{SCHIZOPHRENIA}

thizophrenia is the most prevalent and dispsychotic disorder and is characterized by ly age of onset, symptoms such as halluci, delusions, disordered thinking (positive ms), and impoverished motivation and feelegative symptoms). A genetic predisposition blished, although beyond this there is much roversy regarding etiology, which may be mulSchizophrenia is defined phenomenologiand may subsume a number of clinical synmes.

PET studies of schizophrenia date from 1980 ary according to the group studied and the ique used. The most extensively used PET ies have been measurements of cerebral flow, metabolism, and receptor binding in ts by comparison with controls. Patients have classified according to standardized diagnosstems and this approach assumes regional glogic features common to clinically defined romes of schizophrenia. No such relationship regional pathologic changes has been found. Some early studies of regional cerebral blood $\mathrm{I}(\mathrm{BF})$ in schizophrenia using xenon inhalalechniques suggested a relative decrease in regions. ${ }^{1-3}$ Despite methodologic probwith these pioneering studies, associations ged between abnormal patterns of perfusion pecific symptoms. In general, patients with owest frontal rCBF tended to be the most trann, mute, and indifferent. This pattern of frontality therefore is a finding antedating and remains important and controversial.

Hypofrontality, a relative reduction in prealcortical blood flow or metabolism, has been 4y reported using PET. ${ }^{4-7}$ Despite this, there anuing controversy regarding its reproducispecificity, sensitivity to the confounding efold drugs, and dependence on cognitive state - iptoms. Three studies using deoxyglucose as tholictracer, which yielded contradictory restill be considered.
DeLisi et $\mathrm{al}^{8}$ studied patients with chronic schizophrenia and matched controls. The patients met strict DSM-II criteria for schizophrenia and were medication free for at least 2 weeks prior to the study. Patients had significantly lower anterior to posterior ratios (eight of the nine patients had ratios less than 1). Cerebral atrophy as determined by CAT scan was not associated with this aberrant metabolic pattern. Gur et $\mathrm{al}^{9.10}$ in two communications described abnormalities of the subcorticocortical metabolic gradient in schizophrenic patients who were medication free for at least a week. The duration of illness varied from 3 to 17 years. No evidence for hypofrontality was found. Finally, Szechtman et $\mathrm{al}^{11}$ in a controlled study examined whether neuroleptic treatment duration influenced the regional distribution of metabolism in patients meeting Research Diagnostic Criteria (RDC) for schizophrenia. The patient group was dichotomized according to treatment duration. Both groups had a greater anterior to posterior ratio than control subjects, although this was less evident in the group with the longest neuroleptic exposure.

As in much other work on schizophrenia, the basic findings with PET are often not reproduced. Explanations for these apparently inconsistent results include the confounding effects of treatment and illness duration as well as differences in scanning procedure and in image analysis. An important consideration is the relative preponderance of positive and negative symptoms in the groups studied, which may reflect differing etiologies and pathologies. In this context Liddle ${ }^{12}$ has described three subsyndromes of schizophrenia which include a syndrome of "psychomotor poverty" characterized by negative symptoms (flat affect, poverty of speech and spontaneous movement). Based on a comparison of signs and symptoms in focal brain lesions, it is suggested that this syndrome is associated with impaired dorsolateral prefrontal cortical (DLPFC) function. The prediction that hypofrontality is associated with negative symptoms, within any patient group, has received independent support from PET studies. Delisi et $\mathrm{al}^{13}$ reported that the only significant correlations between relative hypofrontality and symptom ratings were for emotional withdrawal, disorientation, distractibility, and helplessness or hopelessness. Kishomoto et al ${ }^{14}$ discriminated among three distinct types of metabolic pattern in chronic schizophrenic patients. Hypofrontal patients tended to show flat, blunted affect and a hypoparietal group, delusions and hallucinations. Because diagnostic criteria place an emphasis on delusions and hallucinations (positive symptoms), psychomotor poverty syndromes (negative symptoms) are likely to 
be underselected in some study protocols and therefore hypofrontality will be a variable finding across studies.

The possible relationships between negative symptoms, hypofrontality, and putative abnormalities of the mesocortical dopaminergic system have been addressed from a number of perspectives. Animal studies using autoradiography have shown increased frontal and anterior cingulate metabolic response to the dopaminergic agonist apomorphine ${ }^{15}$ Corresponding dopaminergic challenge in humans has yet to be established, although initial studies have been reported. Wolkin et $\mathrm{al}^{16}$ report decreased frontal, temporal, and striatal glucose metabolism in schizophrenic and control subjects following $\mathrm{d}$-amphetamine $(0.5 \mathrm{mg} / \mathrm{kg}$ orally $)$. Geraud et $\mathrm{al}^{17}$ report a reversible hemodynamic hypofrontality in young schizophrenic patients. Hypofrontality was seen in chronic patients whose disease had evolved over more than 2 years, and this pattern disappeared during exacerbation of the symptoms. In a subgroup who had not been treated for several weeks a weak dose of a dopaminergic agonist restored near-normal frontality. The investigators conclude, "This [dopamine hypersensitivity] may reflect either the role of neuroleptic washout or a primitive dopaminergic depletion as proposed by some authors in the chronic form of schizophrenia." 17 This is consistent with a study of patients, characterized by short duration of illness, before and after medication. ${ }^{18}$ In a medication-free state, patients had asymmetric basal ganglia uptake, left greater than right. Following dopamine receptor blockade consequent upon treatment, this asymmetry was abolished, but a left prefrontal cortical reduction in glucose uptake became evident.

Basal ganglia changes in dopamine pharmacology have been reported from postmortem studies of schizophrenia patients, although the findings are confounded by possible drug effects. Increase in $\mathrm{D} 2$ receptors in unmedicated schizophrenic patients has partial support from the PET literature. Wong et al, ${ }^{19}$ using displacement of ${ }^{11} \mathrm{C}$ N-methylspiperone by unlabeled haloperidol, studied D2 receptor density in normal, drug-naive, and treated schizophrenic subjects. A three-compartment model with irreversible radioligand binding was assumed. Significant increases in receptors were reported for both schizophrenic groups, with the increase being more evident in drug-treated patients. There is continuing debate over the reproducibility of these findings ${ }^{20}$ and criticisms of methods of data analysis have been expressed. ${ }^{21}$

Making PET a behaviorally or pharmacologically specific technique is the object of activation by using PET in conjunction with cognitive or sef sorimotor activation. Regional deficits measur with PET can be seen as a common concomitant clinical and neuropsychologic symptoms. This ap proach depends on first establishing the functio anatomy of relevant cortical and subcortical te gions in normal subjects. Weinberger et $\mathrm{al}^{22}$ he reported findings that imply physiologic dysu tion of the prefrontal cortex in response to as cific cognitive challenge, the Wisconsin Card $S$ Using the xenon-133 inhalation technique, the reported that at rest patients had a relative b. not absolute reduction in dorsolateral prefromt flow. During the cognitive activation, the patient showed evidence of impaired augmentation of tili regional flow. These results have yet to be indenes: dently reproduced, and the likelihood that to particular complex task involving a visual, abstrat and motor component is regionally specific is a troversial.

Other, more simple, activation study d have been reported. Cohen et $\mathrm{al}^{23}$ studied cer function during an auditory discrimination designed to emphasize sustained attention. A rect relationship was found between metabolic in the prefrontal cortex and accuracy of pert mance. In schizophrenics lower flow was founc the prefrontal cortex, which was unrelated to performance. Warkentin et al, ${ }^{24}$ again using a non inhalation measurement of $\mathrm{rCBF}$, useda bal fluency task as a cognitive challenge. The marked effect of the activation in normal su was seen in the left prefrontal area, but in schizophrenic group this increase was attenu The investigators conclude, "The controversy garding frontal lobe dysfunction in schizophr is related to whether these areas are function challenged or not." Using "C-deoxyglucose PET tracer, Volkow et $\mathrm{al}^{25}$ studied patients chronic schizophrenia using a smooth pursui tracking activation task. Both at baseline and ing activation, patients displayed absolute an ative frontal hypometabolism. Patients with tive symptoms had lower frontal, temporal. parietal metabolic rates compared with those positive symptoms across both conditions. $S$ cant between-condition differences were ob solely in the positive group. During task mance, significant negative correlations b frontal lobe metabolism and symptom rati peared. This study therefore illustrates the that activation studies may increase not on specificity, but also the sensitivity of PET.

Etiology has not been addressed by PET: ies of schizophrenia. Berman et $\mathrm{al}^{26}$ have exter their xenon inhalation technique, in conju with Wisconsin Card Sort, to studies of 
ic twins concordant and discordant for phrenia. Their findings suggest that the physiologic defect in prefrontal function is for the schizophrenic twin in a discordant urthermore, lifetime neuroleptic medication not explain differences in hypofrontality in mcordant pairs. This finding, which needs iation with PET, may suggest that hypofronis not directly mediated by the genotype.

n conclusion, PET studies of schizophrenia st a pattern of hypofrontality in some groups ients diagnosed as schizophrenic. Hypofronis best correlated with a clinical psychomotor y syndrome with predominantly negative toms. The functional state at the time of scancan greatly change the nature of the findings, this is best exemplified by studies using actiparadigms. Much work needs to be done fine and develop activation strategies both tive and pharmacologic. Their combined use the possibility of linking abnormal neuronission, behavioral impairment, and regional logic changes in schizophrenia.

\section{AFFECTIVE DISORDERS}

The etiology of affective disorders is still unn. The most widely accepted viewpoint posits onal disturbances of neural networks in critrincenters concerned with mood regulation. mal neural transmission in monoaminergic aus has been implicated by the advent of poatidepressant drugs. No specific monoamisystem abnormality in affective disorders yet been identified using indirect methods. failure has frequently been attributed to the direct measures of brain function in vivo. compared with studies of schizophrenia, are relatively few PET studies of affective paand most of those reported have focused on iasurement of cerebral blood flow (CBF) and bolism. Early studies used the xenon inhalaechnique. These will be discussed as a prelimto a consideration of PET studies.

ludies of $\mathrm{CBF}$ in affective disorders, using xenon inhalation technique, have suggested alized decreases in $\mathrm{CBF}$ in depressed pa5. Nathew et $\mathrm{al}^{27}$ studied 13 young patients in age- and sex-matched control group. The ats met RDC for depression and had a mediwashout period of 2 weeks. A generalized ase in cerebral blood flow was reported in the ns compared with control subjects. An inrelationship was observed between blood and an index of illness severity. The princiindings were replicated by a number of sepa- rate investigators, who likewise reported decreased $\mathrm{CBF}$ in depressed compared with control subjects. ${ }^{28,29}$ Uytdenhoef et $\mathrm{al}^{30}$ reported changes of a different kind in a study of unipolar and bipolar patients, the latter while in remission. Significant left frontal hyperperfusion and right posterior hypoperfusion were seen in the depressive compared with control subjects. This pattern was not observed in the euthymic bipolar patients, suggesting that alterations in $\mathrm{rCBF}$ in depression might be state dependent. These findings were not replicated in a number of other reports. Gustafson et $\mathrm{al}^{31}$ compared a heterogeneous group of patients, including depressives, with normal controls and failed to find differences across groups. Other studies of depressed and manic subjects ${ }^{32}$ and depressed patients alone ${ }^{33}$ failed to find differences from controls.

A single study of depressed patients, using the xenon technique, has used an activation paradigm. Patients were studied in the resting state and during performance of both a verbal and a spatial task. ${ }^{34}$ Although no overall differences were apparent between groups during rest, differences emerged in the rCBF patterns of depressive and control subjects during cognitive activation. The depressed female patients had higher than normal flow in all states, whereas the depressed male patients had lower resting flow that became normal during cognitive activation.

The earliest study of affectively ill patients using PET compared regional cerebral metabolic rate of glucose (rCMRglu) values in schizophrenic, affective disorder, and control subjects using a somatosensory paradigm (subjects received $1 / \mathrm{sec}$ electric shocks to the right forearm) which attempted to control for the ambient state across subjects. ${ }^{35}$ The affective patients showed a reduced anteroposterior gradient in glucose metabolism compared with control subjects. The order of magnitude of these changes is indicated by an investigation that demonstrated a similarity in the metabolic rates for glucose between patients with depression and those with multi-infarct dementia. ${ }^{36}$ Only a single report to date has failed to find altered cerebral metabolism in depression. ${ }^{37}$ No differences were found in cerebral glucose utilization in a heterogeneous group of chronic psychiatric patients, including six chronic depressives, and normal control subjects. The small sample size and the chronic population studied limit and complicate the interpretation of this study.

In contrast to these preliminary reports a detailed series of studies of affective patients using ${ }^{18} \mathrm{~F}$ deoxyglucose as a metabolic tracer has been reported. ${ }^{38-40}$ In the first of these, unipolar and bipolar patients were studied under a variety of con- 
ditions. The unipolar group were scanned in a drug-free baseline state, following administration of methylphenidate and when euthymic on followup. The bipolar patients were studied either in a manic or depressed phase and when euthymic on follow-up. An interesting observation was that the bipolar depressed patients in the resting state had lower hemispheric metabolic rates for glucose than either control subjects, unipolar depressed or bipolar manic patients. A subgroup of unipolar depressed patients were identified who had metabolic asymmetries, most prominent in the posteroinferior frontal areas. In this latter group a positive clinical response to methyphenidate was associated with normalization of metabolic asymmetries, whereas an absent clinical response was associated with persistence of asymmetries.

In a subsequent communication on an enlarged series of patients, including unipolar depressives, bipolar depressives, a bipolar mixed group, a manic group, and a control group, the bipolar depressed and the mixed bipolar patients were reported as displaying lower supratentorial whole-brain glucose metabolic rates than any of the comparison groups. ${ }^{39}$ Patients with unipolar depression had significantly lower metabolic ratios of caudate nucleus to whole hemisphere values than either the other patient groups or control subjects. The data further suggested, like the xenon studies, that global hypometabolism in the depressed bipolar patients was state dependent because the metabolic rates "normalized" when patients were euthymic or in a manic phase.

The possibility of a common pathophysiologic basis for the behavioral expression of depression was investigated in a study that examined cerebral metabolic rates in a heterogeneous group of depressives, patients with obsessive compulsive disorders with or without major depression, and normal control subjects. ${ }^{40} \mathrm{~A}$ significant lowering of metabolic rates for glucose in the left dorsal anterolateral prefrontal cortex was reported in patients with primary depression, unipolar and bipolar, by comparison with other groups. Similar results, although less marked, were obtained for the right dorsal anterolateral prefrontal cortex. Obsessive compulsive patients with depression displayed lower metabolic values in the same regions as patients with primary depression. Glucose metabolic rates in the left anterolateral prefrontal cortex correlated significantly with severity ratings of depression. Following clinical response to medication, the metabolic pattern became normal. The investigators concluded that the findings suggested a left anterolateral prefrontal cortex abnormality in major depression. non, of affectively ill patients are consistent inf ing decreased cerebral metabolism, greatestii inferior frontal region, during the depresseds No theoretical framework has been articulate accommodate these findings with conventi theories of monoaminergic function in depres The findings have considerable face validity in mood changes are a frequent concomitant of tal lobe pathologic states. Although the findin: decreased frontal metabolism are reminiscer those reported in schizophrenic patients, the anatomic resolution of early PET techniques not exclude subtle focal differences between nosologically distinct patient groups.

\section{OBSESSIONAL DISORDERS}

Obsessional compulsive disorders $(0 C$ among the most disabling nonpsychotic psy disorders and occur in pure form or as sece phenomena in other psychiatric disorders, ularly depression, and in primary neurolo orders. This association with neurologic di and the similarities between intrusive ideat OCD and intrusive motor acts, such as tics, to the hypothesis that OCD may be secon dysfunction in basal ganglia or related s This hypothesis is now amenable to direct by PET.

Baxter et $\mathrm{al}^{41}$ compared metabolic rat glucose in 14 patients with OCD, normal 0 subjects, and patients with primary depress significant increase in the metabolic rate in th orbital gyrus, a nonsignificant increase in th orbital gyrus, and a bilateral increase in $c$ metabolism, specific to patients with $O C D$ observed. Changes in the caudate to hemi metabolic ratio exclusive to medication-resp OCD patients were also reported. In a study, OCD patients with and without depression were compared with normal subjects. Metabolic rates in the OCD patie depression were significantly lower in the terolateral prefrontal cortex compared w patients without depression, a metabolic similar to that seen in patients with depression. A single study of five patie Gilles de la Tourette syndrome, a condition invariably associated with obsessional phe has also reported increased metabolism in ganglia. ${ }^{42}$

PET studies therefore support the h that obsessional disorders are associated in tional changes in the basal ganglia and th lobes. Because OCD is responsive to $p$ 
harmacologic treatment it would be of interestablish the effects such interventions might on cerebral metabolism. The findings if essed would have a major impact on the nosostatus of OCD, which has traditionally been thed as a neurotic disorder with a presumed iologic etiology.

\section{ANXIETY AND PANIC DISORDERS}

Recurrent, discrete, episodic, and spontanesanxiety attacks are the principal features of c disorder (PD). Its nosology is controversial lit generally is considered as a form of anxiety, ough there is a viewpoint that PD is a sepaenosologic entity with unique pathophysiologic racteristics. A feature of $\mathrm{PD}$ is that it may be masked in susceptible patients by sodium lactate tision.

The relationship between panic disorder and viety has been investigated using PET. ${ }^{43}$ Cereblood flow was measured in patients with a ory of panic disorder and control subjects. groups of patients with PD were identified, sely, patients with positive and negative lactate onse. Whole brain and hemispheric CBF was asured as well as specific brain regions, includthe hippocampus and parahippocampal gyrus. differences were found between groups for le brain or hemispheric CBF, but the left to it CBF ratio differed in the parahippocampal is of the lactate responders. In an extension of study, with the addition of further patients $\triangle P D$ and control subjects, the finding was repied and in addition asymmetries of blood voland oxygen metabolism were found. The pais with $\mathrm{PD}$ also had higher whole brain oxygen etabolism. ${ }^{44}$

The relationship between anxiety, panic diser, and normal anticipatory anxiety was instigated in a study of subjects at rest and dur7y sodium lactate infusion. ${ }^{45}$ During periods of tate-induced anxiety, there were increases in $\triangle B F$ in the anterior temporal poles, insular corex, daustrum, lateral putamen, the vicinity of the giverior colliculus, and left anterior cerebellar ver. There was no increase in $\mathrm{rCBF}$ in the nonic and control subjects. A separate study meared $\mathrm{rCBF}$ in subjects while they anticipated a inful electric shock. ${ }^{45}$ In these subjects anticiparyanxiety was associated with an increase in $\mathrm{CBF}$ the temporal poles.

Both these latter studies suggest a common ahway for the expression of anxiety, involving snictures in the temporal poles, and relate well to recent conceptualizations of the pathophysiologic basis of anxiety. ${ }^{46}$ Studies of patients with PD provide intriguing evidence that this condition has a biologic basis separate from generalized anxiety.

\section{NEUROPSYCHIATRIC DISORDERS}

Psychiatric morbidity, both psychotic and nonpsycho:ic, is common in primary neurologic illness. The application of PET to the study of such neuropsychiatric disorders should greatly extend our knowledge of brain-behavior relationships and clarify pathophysiologic mechanisms mediating primary psychiatric disorders. The mechanisms by which focal brain insults result in neuropsychologic impairment is open to study. Few PET studies, with notable exceptions, have extended their boundaries beyond either a primary neurologic or psychiatric perspective. A full review of PET in neuropsychiatric disorders is beyond the scope of this article: two studies will be considered as illustrative of the potential application of PET in neuropsychiatric research.

A wide range of clinical manifestations are recognized following isolated infarcts of the thalamus, including verbal and visual memory impairment, aphasia, neglect, and behavioral change. A clinicopathologic perspective might suggest that these impairments reflect a critical role for the thalamus in these diverse psychologic functions. However, findings from PET investigations of such patients with thalamic lesions provide a different viewpoint, suggesting that neuropsychologic impairment relates to remote physiologic effects rather than the direct pathologic effects of lesions. Baron et $\mathrm{al}^{47}$ in a combined PET and neuropsychologic study of ten patients with single isolated unilateral lesions of the thalamus reported that nine of ten displayed significant and widespread ipsilateral cortical hypometabolism remote from the lesion. These patients also displayed a range of neuropsychologic impairments with a marked trend for deficits to be related to degree of cortical hypometabolism.

Depression is a common accompaniment of Parkinson's disease and may frequently antedate the onset of motor impairment. Its relationship to the disorder is controversial and has been conceptualized as a psychologic reaction to the motor disability. Mayberg et $\mathrm{al}^{48}$ have investigated the relationship between cerebral glucose metabolism and mood disorder in parkinsonian patients. Depressed parkinsonian patients had a significant decrease in rCMRglu in the orbital and inferior prefrontal cortex compared with nondepressed patients and control subjects. A significant corre- 
lation emerged between ratings of mood severity and rCMRglu in these regions. It is tempting to speculate that the decreased metabolism was related to loss of extrastriatal ascending monoaminergic projections, since destruction of these pathways in primates is associated with decreased frontal metabolism.

\section{SUMMARY}

PET is potentially the most powerful tool yet available for the direct, in vivo investigation of the biologic basis of psychiatric and neuropsychiatric disorders. The fulfillment of its potential rests on the development of methodologies and study design appropriate to psychiatric disorders. To date, findings in both schizophrenia and affective disorder, using protocols largely based on resting state data acquisition, suggest altered regional metabolism. These approaches need to be extended, particularly by the application of protocols that utilize PET to obtain longitudinal data under controlled experimental situations. In two conditions traditionally ascribed to psychologic causes, OCD and $\mathrm{PD}$, there is intriguing evidence of specific biologic abnormalities, which, if confirmed, would lead to a fundamental revision of their nosologic status. In neuropsychiatric disorders PET findings, although preliminary in nature, offer an alternative paradigm to traditional clinicopathologic correlations by suggesting that clinical impairments relate to physiologic effects at sites distant from structural lesions.

\section{REFERENCES}

1. Ingvar DH, Franzen G. Distribution of cerebral activity in chronic schizophrenia. Lancet 1974;2:1484-6

2. Ingvar DH, Franzen G. Abnormalities of cerebral biood flow and metabolism in chronic schizophrenia. Acta Psychiatr Scand 1974;50:425-62

3. Smith MR, Brodie JD. Positron emission tomographic studies in schizophrenia: a review. In: Trimble M, ed. New brain imaging techniques and psychopharmacology. Oxford: Oxford University Press, 1986;35-48

4. Widen I, Bergstrom M, Blomqvist G, et al. Glucose metabolism in patients with schizophrenia-emission computed tomography measurements with $11 \mathrm{C}$-glucose. J Cereb Blood Flow Metab 1981;1(Suppl 1):4556

5. Farkas T, Wolf AP, Jaeger J, et al. Regional brain glucose metabolism in chronic schizophrenia. Arch Gen Psychiatry 1984;41:293-300

6. Wolkin A. Jaeger J, Brodie JD, et al. Persistence of metabolic abnormalities in chronic schizophrenia as determined by positron emission tomography. Am J Psychiatry $1985 ; 142: 564-71$

7. Wolkin A, Angrist B, Wolf A, et al. Low frontal glucose utilization in chronic schizophrenia: a replication study. Am J Psychiatry 1988;145:251-3 emission tomography in schizophrenic patients and without neuroleptic medication. J Cereb Flow Metab 1985;5:201-6

9. Gur RE, Resnick SM, Alavi A, et al. Regional brain tion in schizophrenia I. A positron emission Arch Gen Psychiatry 1987;44:119-25

10. Gur RE, Resnick SM, Gur RC, et al. Regional brain tion in schizophrenia II. Repeated evaluation positron emission tomography. Arch Gen Psyc 1987:44:126-9

11. Szechtman H, Nahmias C, Garnett S, et al. Effecto roleptics on altered cerebral glucose metabolis: schizophrenia. Arch Gen Psychiatry 1988;45:522-

12. Liddle PF. The symptoms of chronic schizophrenia: examination of the positive negative dichotom Psychiatry 1987;151:145-51

13. DeLisi LE, Buchsbaum MS, Holcomb HH, et al. of correlates of decreased anteroposterior metabolic; dients in positron emission tomography (PET) of 8 ophrenic patients. Am J Psychiatry 1985;142:78-5

14. Kishimoto H, Kuahara H, Ohno S, et al. Three sut of chronic schizophrenia identified using $11 \mathrm{C}-\mathrm{g}_{\mathrm{t}}$ positron emission tomography. Psychiatry Res. 21:285-92

15. McCulloch J, Saraki HE, McCulloch MC, et al. Th tribution of alterations in energy metabolism in brain produced by apomorphine. Brain Res 243:67-80

16. Wolkin A, Angrist B, Wolf A, et al. Effects of an amine on local cerebral metabolism in norma schizophrenic subjects as determined by positron sion tomography. Psychopharmacology (Berl) 198 241-6

17. Geraud G, Arne Bes MC, Guell A, Bes A. Revers of haemodynamic hypofrontality in schizophre Cereb Blood Flow Metab 1987;7:9-12

18. Widen I, Greitz T, Litton JE, et al. PET studies o cose metabolism in patients with schizophrenia $1983 ; 4: 550-2$

19. Wong DF, Wagner HN, Tune LE, et al. Positrone tomography reveals elevated D2 dopamine re in drug näive schizophrenics. Science 1986;234 63

20. Farde L, Wiesel FA, Hall $\mathrm{H}$, et al. No D2 recep crease in PET study of schizophrenia. Arch G chiatry 1987;44:671

21. Zeeberg BR, Gibson RE, Reba RC. Elevated D2 mine receptors in drug näive schizophrenics. 1988;239:789-91

22. Weinberger DR, Berman KF, Zec RF. Ph dysfunction of the dorsolateral prefrontal $c$ schizophrenia: 1 Regional cerebral blood dence. Arch Gen Psychiatry 1986;43:114-24

23. Cohen RM, Semple WE, Gross M, et al. Dysfuncin prefrontal substrate of sustained attention in phrenia. Life Sci 1987;40:2031-9

24. Warkentin S, Nilsson A, Risberg J, Karlson S. Abs frontal lobe activation in schizophrenia. J Cereb Flow Metab 1989;9(Suppl 1):S354

25. Volkow ND, Wolf AP, Van-Gelder P, et al. Phen logical correlates of metabolic activity in 18 p with chronic schizophrenia. Am J Psychiatr? $144: 151-8$

26. Berman KF, Torrey EF, Daniel DG, Weinberger frontal cortical blood flow in monozygotic th cordant and discordant for schizophrenia. Blood Flow Metab 1989;9(Suppl 1):S591

27. Mathew RJ, Stirling-Meyer J, Francis DJ, et al. C blood flow in depression. Am J Psychiatry 137: 1449-50

28. Warren LR, Butler RW, Katholi CR, et al. Focalc in cerebral blood flow produced by monetaryinc during a mental mathematics task in normal a pressed subjects. Brain Cogn 1984;3:71-85

29. Sackeim HA, Prohovnik I, Apter F, et al. Regio 
bral blood flow in affective disorders; baseline and effets of treatment. In: Takahashi R, Flor-Henry P, Gruzelier J, Niwa F, (eds): Cerebral dynamics, lateralily, and psychopathology. New York: Elsevier, 1987 indenhoef $\mathrm{P}$, Portelange P, Jacquy J, et al. Regional cerebral blood flow and lateralized hemispheric dysfuncton in depression. $\mathrm{Br}_{\mathrm{r}}$ J Psychiatry 1987; 143, 128-32 bustafson L, Risberg J, Silfverskiold P. Cerebral blood flow in dementia and depression. Lancet 1981;1:275 sifverskiold P, Risberg J. Regional cerebral blood flow in depression and mania. Arch Gen Psychiatry 1989; 46:253-59

Goldstein P, Brown GG, Welch K, et al. Age-related decline in $\mathrm{rCBF}$ in schizophrenia and major affective disorder. J Cereb Blood Metab 1985;5(Suppl 1):203-4

Gur RE, Skolnick BE, Gur RC, et al. Brain function in osvehiatric disorders. Arch Gen Psychiatry 1984;41: $695-9$

buchsbaum MS, DeLisi I.E, Holcomb HH, et al. Anteroposterior gradients in cerebral glucose use in schizophrenia and affective disorders. Arch Gen Psychiatry 1984;41:1159-66

Ruth DE, Metter EJ, Riege WH. Patterns of cerebral glucose utilization in depression, multiple infarct demenlia and Alzheimer's disease. Res Publ Assoc Res Nerv Ment Dis 1985;63:211-26

xing AS, Metter EJ, Riege WH, Kuhl DE: Comparison of PET measurement of local brain glucose metabolism and CAT measurement of brain atrophy in chronic schizophrenia and depression. Am J Psychiatry 1986; $143: 175-80$

Baxter LR Jr, Phelps ME, Mazziotta JC, et al. Cerebral metabolic rates for glucose in mood disorders. Arch Gen Psychiatry $1985 ; 42: 441-7$
39. Schwartz JM, Baxter LR, Jr, Mazziotta JC, et al. The differential diagnosis of depression. JAMA 1987;258: $1368-74$

40. Baxter LR, Jr, Schwartz JM, Phelps ME, et al. Reduction of prefrontal cortex glucose metabolism common to three types of depression. Arch Gen Psychiatry 1989; $46: 243-50$

41. Baxter LR, Jr, Phelps ME, Mazziotta JC, et al. Local cerebral glucose metabolic rates in obsessive-compulsive disorder. Arch Gen Psychiatry 1987;44:211-8

42. Chase TN, Foster NI., Fedio P, et al. Gilles de la Tourette syndrome: studies with the fluorine-18-labeled fluorodeoxyglucose positron emission tomographic method. Ann Neurol 1984;15(Suppl):S175

43. Reiman EM, Raichle ME, Butler FK, et al. A focal abnormality in panic disorder, a severe form of anxiety. Nature 1984;310:683-5

44. Reiman EM. The study of panic disorder using positron emission tomography. Psychiatr Dev 1987;5:63-78

45. Reiman EM, Raichle ME, Robins E. Involvement of temporal poles in pathological and normal forms of anxiety. I Cereb Blood Flow Metab 1989;9(Suppl 1):S589

46. Gray JA. The neuropsychology of anxiety. Oxford: Clarendon, 1982

47. Baron JC, Antona RD, Pantano P, et al. Effects of thalamic stroke on energy metabolism of the cerebral cortex. A positron tomography study in man. Brain $1986 ; 109: 1243-59$

48. Mayberg HS, Starkstein SE, Bolduc P, et al. Frontal lobe hypometabolism in depressed, nondemented patients with Parkinson's disease. J Cereb Blood Flow Metab 1989;9(Suppl 1):346 